\title{
"A velha praga": considerações sobre a construção de um modelo civilizacional para o camponês paulista
}

\author{
Carla Julião da Silva ${ }^{1}$ \\ Recebido em março de 2021 \\ Aceito em junho de 2021
}

\begin{abstract}
RESUMO
O presente artigo apresenta reflexões sobre raça e os caminhos da modernização econômica no meio rural paulista. Modelos e projetos civilizatórios foram oferecidos no sentido de chegar a um arquétipo de nação como proposta sobre o sentido do uso e costume da terra e o lugar reservado ao negro no imaginário paulista ao longo do século XX. Faremos uma breve contextualização para compreender tais transformações, caminhando entre as leituras de obras literárias, como "Urupês" de Monteiro Lobato e trabalhos científicos para compreender as representações no diz respeito à naturalização, as heranças sociais e econômicas da condição rural, modernização, globalização econômica e atuação de cooperativas em bairros rurais atualmente.
\end{abstract}

Palavras- chave: Identidade Rural; Raça; Globalização Econômica.

\section{"The old plague": considerations on the construction of a civilizational model for peasants paulista}

\begin{abstract}
This article presents reflections on race and the paths of economic modernization in rural São Paulo. Civilizatory models and projects were offered in order to arrive at an archetype of nation as a proposal on the meaning of land use and custom and the place reserved for blacks in the São Paulo imagination throughout the 2oth century. We will make a brief contextualization to understand such transformations, walking between the readings of literary works, such as "Urupês" by Monteiro Lobato and scientific works to understand the representations regarding naturalization, the social and economic legacies of the rural condition, modernization, economic globalization and operation of cooperatives in rural neighborhoods today.
\end{abstract}

Keywords: Rural Identity; Race; Economic Globalization.

A “velha praga”, que dá o título a este artigo encontra-se na obra clássica de Monteiro Lobato "Urupês" (1978), faz referência ao caboclo paulista descrito como um ser inadaptável à civilização, parasita da terra. A obra "Urupês", que ganhou notoriedade

\footnotetext{
${ }^{1}$ Mestra em Ciências Sociais pela Universidade Estadual Paulista (UNESP), campus de Marília/SP. Lattes: http://lattes.cnpq.br/3754923942849948 Email: carlajuliaosilva@gmail.com.
} 
dentro e fora da literatura, deu vida ao personagem Jeca Tatu. Dito que nada tinha de assustador para uma época de que o atraso nacional estava vinculado ao "o tipo clássico do sitiante já com pé fora da classe”, um claro diagnóstico de que os problemas civilizatórios da sociedade brasileira estavam associados na indolência, preguiça e ignorância das populações rurais. Também, nada nos estranha, que o nome dado à obra seja inspirado num tipo de cogumelo parasitário que destrói a madeira, o urupê.

A urbanização era decorrência natural e inevitável da modernização da sociedade e serviram como sustentação de argumentos sobre a dicotomia entre campo e cidade $\mathrm{O}$ espaço rural ainda hoje é definido no imaginário social como mundo não urbano vinculado à visão de um mundo agrário com características naturalizadas rurais e com mínimas transformações, além da diminuição da população agrícola como consequência da efetivação hegemônica do modelo produtivista. O mito fundador da Sociologia Rural que instituiu a oposição entre campo e cidade numa relação de subordinação da primeira pela segunda como realidades espaciais e sociais descontínuas. A busca da essência do rural e do urbano envolveu um amplo debate ao longo do século XX que, dos muitos estudiosos sobre o tema como os autores Antonio Candido, Maria Isaura de Queiroz e Carlos Brandão - buscaram, em seu tempo, os caminhos analíticos no desenvolvimento das apreciações de rural a partir das perspectivas de sua modernização (CARNEIRO, 2008, p. 10-11).

Tais discussões ampliaram-se devido a pesquisas que abordam questões de produção agrária, contingente populacional na área rural e até mesmo na literatura, que este último, teve um papel significativo na construção do imaginário social devido suas interpretações e descrições sobre o ambiente e as condições dos moradores rurais em destaque aqui o Estado de São Paulo.

O título deste artigo nos conduz a refletir sobre como somos levados a naturalizar modos de vida, reproduzir representações sociais de um grupo e o seu lugar ocupado na sociedade que, consequentemente, direciona a pré-conceitos sobre um determinado grupo ou sua possível inferioridade na hierarquia social ressaltando que as diferenças sociais e culturais estão vinculadas a sua escolaridade, posição econômica, o desigual, o dessemelhante e o desconhecido e os que detêm de posições sociais privilegiadas Tal indagação leva a sensibilização do nosso olhar crítico sobre 
questões relacionadas a etnocentrismos e racismos pautados em problemas econômicos, políticos, sociais e raciais.

Estudos como de Giralda Seyferth (1995) auxilia a pensarmos o poder dos estereótipos e da questionável superioridade da raça branca europeia, sendo a cor da pele uma característica classificatória impondo um discurso do racismo em pressupostos da desigualdade biológica entre a espécie humana, envolvendo assim as chamadas "raças inferiores" (não brancos), as "classes inferiores", o "sexo inferior", os "grupos étnicos inferiores", a "ralé pululante" (os mestiços em geral). No Brasil, assistimos o postulado de uma política intensa de incentivo a imigração branca pautada no discurso civilizacional que resultou na estratificação social, sustentadas por pesquisas científicas como de Nina Rodrigues e Oliveira Vianna que também estiveram presentes na literatura como em obras de Euclides da Cunha e Monteiro Lobato. Segundo Seyferth as diferenças de raça são utilizadas para separar pessoas e designar seu lugar na sociedade e sua posição de inferioridade social. Os traços determinantes das diferenças impõem também uma identidade negativa, genérica e pejorativa como vemos vinculada as identidades regionais de migrantes provenientes da região Norte e Nordeste, atribuindo traços fenótipos associados à inferioridade ou à incivilidade sobre uma categoria genérica de "nordestino”, "baiano”, “paraibano” (SEYFERTH, 1995, p.183187).

É sob esta pertinente reflexão guiará a discussão apresentada neste artigo. A construção de diferenças pode ser relacionada à construção de representações sociais? Quando nos referimos a estudos do universo rural o tema, geralmente, está relacionado a somente questões econômicas, produção de alimentos e avanços no agronegócio? Por que as identidades de raça e classe estão sustentadas na origem biológica e tem papel central na desqualificação social? Caipira é aquele que tem hábitos e modos rudes, devido a pouca instrução, escasso convívio social ou é uma construção arraigada no imaginário popular e se manifesta através dos estereótipos?

Ainda que rapidamente, lancemos um olhar retrospectivo sobre esse debate, de modo a elucidar de onde partem as questões que pretendemos discutir no transcorrer do presente artigo expandindo os questionamentos sobre o que sabemos do termo "caipira”, quais elementos de discriminação associados a uma posição social 
ou um comportamento "não civilizado" que carrega traços classificatórios pela origem ou aparência da população que ocupou a área rural. A reflexão perpassa pelo sentido, uso e o costume da terra, as representações sociais construídas que reforçaram um entendimento sobre o morador do campo, tal como os modos de vida, a linguagem e os termos jocosos relacionados às más condições de saúde dos moradores rurais, principalmente no Estado de São Paulo que ganharam visibilidade ao longo do século XX e perpetuam até hoje no imaginário social.

\section{O sentido no uso e costume da terra e o lugar reservado ao negro no Estado de}

\section{São Paulo}

Compreender as transformações ocorridas na área rural paulista é preciso abranger o contexto e a formação o Estado de São Paulo seiscentista, levando em conta o sentido escravista no uso, costume e um possível lugar do indivíduo negro na sociedade. Para John Manuel Monteiro (1994) sentido da escravidão em São Paulo se desenvolveu a partir dos princípios de exploração econômica, num primeiro momento utilizando-se de mão-de-obra indígena, mas nos moldes da exploração da mão-de-obra negra que já acontecia no litoral do estado. Os paulistas tentaram racionalizar e justificar tal prática assumindo, de forma absoluta, o controle do trabalho indígena.

Um novo modo de vida se espalhou em locais onde havia núcleos de mineração, produção artesanal e mantimentos de animais se expandiram neste período. Diversas expedições para penetrar em regiões como Vale do Paraíba, dando origem a novas vilas como a de Itu, Sorocaba e Curitiba por pioneiros paulistas. Em São Paulo, à busca de ouro para uma economia agrícola apressou as derrubadas e queimadas para adquirir novas áreas para plantio, serviços e outros bens. Pelo sistema das fazendas ocorre a intensificação da utilização de mão-de-obra escrava e recorrendo depois para a imigração europeia maciça que colocou milhares de trabalhadores à disposição da lavoura comercial. Segundo Darcy Ribeiro (2006) a escravidão indígena já não estava suprindo as demandas, tampouco possuíam a escravaria negra e o morador do campo, marginalizado, passa para condição de dependência e sem a posse de terras. Esse processo de mudanças, tanto na forma de produzir e quanto nas 
estratégias para intensificar a produção com a demanda de mão de obra, desencadearam consequências sociais e econômicas que resultaram num crescente número de pessoas negras que embora livres, ainda trabalhavam em condições de escravidão, e a criação do proletariado industrial no final do século XIX e início XX.

Em São Paulo, durante a vinda dos imigrantes europeus, a maioria de artesãos e operários especializados (proprietários de pequenos negócios) eram pardos e pretos livres. Censos realizados entre 1900 e 1920 nada revelam a inserção dos negros na sociedade pós-abolição, entretanto já circulavam jornais e revistas voltados aos negros, como, por exemplo, os periódicos A Pátria e O Progresso no ano de 1899 em São Paulo, O Exemplo em Porto Alegre, em 1892. ${ }^{2}$ Embora mantivessem propostas diferentes, a grande maioria buscava expressar a necessidade da educação para a população negra e apontar o estigma racial que classificam negros e mulatos como pessoas sem capacidade intelectual, desse modo, fixava a atenção orientando-os para o mercado de trabalho ao final do século XIX e ao longo do século XX.

$\mathrm{Na}$ década de 1920, a formação de uma pequena classe média, “esmagadoramente" branca passa a ganhar espaço em São Paulo e tais periódicos tornaram-se meios de denúncia das dificuldades na inserção na sociedade paulista, da desigualdade social entre negros e brancos e das restrições sofridas em decorrência do preconceito racial. O agrupamento de todas as publicações passaram a ser conhecido como Imprensa Negra Paulista. Dentro deste mesmo período, em 1931, é fundado movimento a Frente Negra Brasileira que viria a se transformar em partido político, extinto com os demais na criação do Estado Novo.

Segundo George Reid Andrews (1951), os dados levantados a partir de 1940, demonstra que de uma população negra de 862.255 somente 623 possuíam negócios não agrícolas e cerca de $15 \%$ dos pardos e pretos compunham a força de trabalho agrícola em São Paulo. O setor público foi à única área que os afro-brasileiros conseguiram uma paridade. Em 1940, a população afro-brasileira em idade produtiva em São Paulo era de $12 \%$ e desta porcentagem 8,8\% estavam em setores públicos, porém, bem distantes do status de classe média, se encontravam em trabalhos servis

\footnotetext{
${ }^{2}$ ARAUJO, Valmir Teixeira de. "O papel da imprensa negra brasileira". In: Revista Alterjor, 2019.
} 
como varredores de rua, trabalhadores de construção, porteiros e serviços de escritório mal remunerados como mensageiros e serventes. Quando as ocupações são mencionadas, frequentemente era de professores nas escolas públicas, escriturários e funcionários de nível inferior do serviço postal, coleta de impostos estadual, do governo municipal ou de agências semioficiais como a companhia telefônica.

A discriminação de cor permanecia presente em São Paulo, houve denúncia dos jornais negros como Getulino (1923), O Combate (1915), O Clarim da Alvorada (19241932), A Voz da Raça (1933-1937), as colunas sociais destes jornais deixavam claro a importância do emprego federal, estadual e municipal da base econômica para uma pretensa elite negra. Para George Reid Andrews, a doutrina da democracia racial isentava a política do Estado de qualquer responsabilidade adicional pela situação da população negra, até mesmo transferiu-a diretamente nos ombros dos próprios afrobrasileiros, aqueles que questionassem a noção de democracia racial corriam o risco de ser confrontados com uma análise detalhada das falhas deficiências do grupo racial ao qual pertenciam. ${ }^{3}$

Segundo Darcy Ribeiro (2006), o domínio e uma nova forma de vida da área rural paulista dispersaram os povoados que se concentravam nesta região, a população caipira que estava integrada em bairros, desgarrou deste convívio, foi condicionada ao um horizonte culturalmente limitado, desambicioso, ocioso e vadio. $\mathrm{O}$ fator básico desta reordenação social e econômica foi o restabelecimento do sistema mercantil e com ele a valorização das propriedades. O caipira paulista, portanto, se marginaliza, apegando-se a uma condição e independência inviável sem a posse de terras. Mesmo com a existência de milhões de caipiras subocupados.

\footnotetext{
3 Gilberto Freyre é considerado um dos estudiosos fundamentais para a compreensão da formação social brasileira e nos estudos interpretativos do Brasil e do povo brasileiro. O tema da miscigenação foi centro de suas pesquisas e foi a partir do impacto nacional e internacional exposta, principalmente na obra "Casa Grande E Senzala" publicada no ano1933, que na qual, se firmou a noção da suposta "democracia racial brasileira" que, segundo o autor, do contato anterior entre portugueses e povos de pele mais escura, como os árabes, e da consequente flexibilidade racial do brasileiro de origem lusitana - herdeiro da plasticidade característica da sociedade portuguesa, que "abrandou" as relações raciais entre nós. É autor de dezenas de livros, entre os quais, Casa-grande E Senzala (1933); Sobrados e mocambos (1936); Nordeste (1937); O mundo que o português criou (1940); Ingleses no Brasil (1948); Aventura e rotina (1953); Ordem e progresso (1959); Vida, forma e cor (1962) entre outros.
} 
O sistema de fazendas teve que promover primeiro, uma intensificação do tráfico de negros escravos e de apelar, depois, para a imigração europeia maciça que coloca milhões de trabalhadores à disposição da grande lavoura comercial. Confinado nas terras mais sáfaras, enterrado na sua pobreza, o caipira vê, impassível, chegarem e se instalarem, como colonos das fazendas, multidões de italianos, de espanhóis, alemães ou poloneses para substituírem o negro no eito, aceitando uma condição que ele rejeita. Essa nova massa vinha, porém, de velhas sociedades, rigidamente estratificadas, que a disciplinara para o trabalho assalariado, e via na condição de colono um caminho de ascensão que faria dela talvez, um dia pequenos proprietários (RIBEIRO, 2006, p.351 e 352).

A consequência deste sistema de fazendas alargou as desigualdades sociais entre caipiras, brancos, mulatos e negros. Nestas circunstâncias, o contingente de negros, já alforriados, precisou se submeter ainda mais a uma forma de segregação. Em consequência, os motivos econômicos para a realização de investimentos, para atrair ao país colonizador branco, se somaram aos incentivos ideológicos desta prática, a ideia de democracia racial e o branqueamento da população paulista como a imigração europeia, destinados a um melhoramento da raça, colaborou também para a crescente falta de identificação destes caipiras com a sua história que contribuiu para estudos sobre a formação social brasileira. A perspectiva de uma harmoniosa relação entre os três eixos raciais propostos por Gilberto Freyre foi colocada em cheque. Florestan Fernandes (2006) traçou questionamentos sobre esta posição o crítico e investiu esforços na tarefa de investigar os problemas sociais e econômicos da população negra no Brasil. Segundo Gustavo da Silva Kern.

Os estudos de Fernandes se concentraram fundamentalmente em investigar o
problema das condições socioeconômicas da população negra numa sociedade
moderna de classes. De toda uma série de levantamentos a respeito da
situação racial em São Paulo - compilados a pesquisas que foram
empreendidas paralelamente em outras regiões do país - suas análises
chegaram à conclusão de que o preconceito racial era amplamente praticado
no Brasil. Manifestando-se de modo decisivo justamente na dificuldade da
população negra, nas grandes metrópoles, de se inserir como cidadão pleno
numa sociedade institucionalmente liberal e de economia industrial
(KERN,2014, p. 88).

Ao passo em que Gilberto Freyre apontava a miscigenação uma possibilidade de fomentar a igualdade racial, Florestan Fernandes expõe o erro de se apoiar sobre a ideia de que os padrões estariam vinculados a exemplos de tolerância racial sem se 
debruçar sobre os problemas socioeconômicos. Na análise de Gustavo da Silva Kern (2014), Gilberto Freyre propõe um paralelo entre o conceito de raça e de democracia, em que, a noção de raça passa a aparecer como adjetivo de uma categoria política, fundamentando a metáfora da democracia racial. No entanto, as hipóteses de Gilberto Freyre foram confrontadas com a realidade brasileira, não se solidifica quando apresentamos os dados do Censo de 1940 e o contexto em que o mito da democracia racial foi sustentado no Brasil, como foi destacado aqui. Dada a concentração racial da renda, do prestígio social e do poder, a "população de cor" não possui nenhuma vitalidade para enfrentar e resolver seus problemas morais. A inclusão do negro, "mulato" e outras "minorias étnicas, raciais ou nacionais" na programação do desenvolvimento socioeconômico e nos projetos que visem aumentar a eficácia da integração nacional que, na qual, a escolarização, nível de emprego e deslocamento de populações precisariam ganhar enorme relevo. Cabendo ao governo suscitar alternativas e um programa de combate à miséria e a seus efeitos no âmbito dessa população (STEPAN 2005, p.52).

\section{Um modelo social para o projeto de nação}

Desde a Independência, a literatura nacional preocupou-se em construir símbolos que trouxessem à tona imagens e tradições e de elementos de uma essência nacional para fugir de formulações e ligações entre metrópole Portugal e a sua colônia, Brasil. Intelectuais como José Bonifácio de Andrada e Silva ganharam importância nacional já no século XIX, cabendo-lhe liderar setores da elite nativa, freando projetos de recolonização, apoiando D. Pedro para redigir a Constituição do novo regime. De seus escritos emerge um projeto civilizador que tinha por fim viabilizar um modelo de nação, visto que para ele, o brasileiro era dotado, por natureza, preguiçoso, indolente e ignorante, a educação brasileira precisaria ser transformada em um conjunto homogêneo em todos os sentidos: racial, cultural, legal e cívico (SILVA, 200o, p.7).

A possibilidade de ter uma literatura sem traços portugueses ou com tons eclesiásticos revelou-se no sertanismo romântico, no regionalismo do período realistanaturalista e os modernistas, estes últimos principalmente em São Paulo. Mário de 
Andrade, vanguardista do movimento modernista em São Paulo, com obras de grande relevância nacional com a publicação de: "Pauliceia Desvairada" (1922) e o romance que também influenciou a forma de escrever as tradições brasileiras em "Macunaíma" (1928). Monteiro Lobato foi outro escritor paulista que produziu artigos, críticas, crônicas, prefácios, cartas, livros sobre a importância nacional em uma época em que os livros eram editados fora do território brasileiro, assim diante deste cenário, o autor também ganhou notoriedade no Brasil com uma série de renovações nos livros didáticos e infantis e com temáticas relacionadas ao meio rural paulista.

Segundo Serge Gruzinski (2001) a obra de Mario de Andrade "Macunaíma" nos convence que as aparências podem ter um significado de múltiplas transformações. $O$ contexto da mundialização ou a globalização foi o resultado do encontro entre europeus e sociedade indígenas que nos deixaram como herança a resistência, a mestiçagem e o arquétipo do brasileiro e do latino-americano oscilando entre tais culturas, vários traços característicos das sociedades indígenas provem da península Ibérica. A dificuldade pensar a mistura das culturas também pode resultar em interpretações que procedem mais da nossa própria maneira de ver a realidade.

Deste modo, podemos analisar tal questionamento de Gruzinski no contexto brasileiro. Os imigrantes europeus tiveram a doação de terras devolutas do Estado formando colônias, mas mantendo seus sentimentos de um pertencimento étnico europeu. A não adesão ao Brasil, por parte dos imigrantes, como sua nação resultou em fenômenos de rejeição que atualmente observamos. As descrições dos literatos sobre o homem do campo, frisando as diferenças e o destinando sempre o lugar do abjeto, resultaram numa série de preconceitos e imagens essencializadas sobre as pessoas, mesmo assim, com a justificativa de produzir uma literatura nacional e sem traços europeus. Se observarmos a frase tão conhecida do livro de Mario de Andrade "sou um tupi tangendo um alaúde" nos mostra a ambiguidade da busca pela pureza racial brasileira. Assim, desde a colonização.

Por toda a parte, os escravos serviam de moeda de troca: ao longo de todo o século XVII, os índios do rio Negro podiam tanto praticar o trato de escravos como, por sua vez, tornarem-se escravos dos holandeses ou portugueses. Em certos anos os portugueses conseguiam apresar, depois de verdadeiras razias, um bom milhar de nativos, que eram encaminhados em condições horrorosas 
para Belém e Grão-Pará, no extremo oriental da grande floresta. Os sobreviventes se misturavam com as populações locais em miscigenações que se acentuaram ao longo dos anos (GRUZINSKI, 2001, p.32).

A construção de uma identidade torna-se uma tarefa minuciosa, o trabalho para identificar no homem rural algo que o representasse passou por explicações de traços do "baixo povo rural" pelo olhar da "nobreza rural" como lembrar Carlos Brandão (1983, p. 7). Com a perspectiva do avanço do capital no Brasil, a passagem do século XIX para o XX introduziu um novo olhar dos intelectuais na construção de uma identidade brasileira. Foram produzidas múltiplas representações da população, buscando conferir uma identidade nacional que romperia com o passado de dependência e dicotomia campo/cidade foi um dos temas centrais que estimulou o desenvolvimento da produção cultural e científica. É neste momento que o Brasil e seu povo ocuparam lugar central nos debates intelectuais no momento de busca da constituição das especificidades da nação em formação:

Encontrar um tipo étnico específico capaz de representar a brasilidade tornou-se grande desafio a ser enfrentado pela intelectualidade, que tomou para si a missão de encontrar a identidade nacional rompendo com o passado de dependência cultural. Esta identidade, construída ao longo do século XIX, configurou-se em múltiplas imagens que guardavam ambiguidades (PARRILLA, 2006, p.124).

Quando pensamos que todos esses projetos de construções identitárias, embora com interesses genuínos em uma ideia de nação, identidade nacional ou produção de escritas nacionais, afetou diretamente a população negra, caipira, cabocla. O campo tinha papel fundamental neste cenário, passou a ser representado fartamente na literatura paulista do período impulsionada por escritores como Cornélio Pires (1927) e Monteiro Lobato (1957), que deram ao homem do interior paulista representações diversificadas. O termo "caipira" ao longo dos anos foi tomando várias formas de adjetivar o homem do campo e tomaram força até chegar aos dicionários. O significado encontrado no dicionário carrega sinônimo como: Jeca; Matuto; Saquarema. Pessoa nascida ou (que) vive em regiões rurais no interior do estado de São Paulo; tem modos simples e pouca instrução; indivíduo pouco sociável, sem traquejo no convívio social (AULETE, 2011, p. 26o). O habitante do campo ou da roça, em geral, 
de pouca instrução e de modos canhestros, passa a ser identificado como jeca, matuto, roceiro, sertanejo, caboclo, capiau ou tabaréu. É possível observar que conotações como "de pouca instrução" e "jeca" já estão inseridas no cerne da palavra "caipira", naturalizando então a imagem de "homem fora do seu tempo", inapto para a vida urbana. Para o morador do campo a sua representação, consequentemente, estará relacionada a "uma pessoa simples e de pouca instrução" e, mesmo que tenha outros saberes, sua cultura acaba perdendo sentido diante das obrigações da vida citadina.

Luciana Meire da Silva (2013) apresenta a hipótese que o autor Monteiro Lobato criou a representação caricatural do caipira em São Paulo, a chegada dos imigrantes nas indústrias e nas lavouras traria a esperança para a superação da decadência nacional particularmente pela sua disciplina em relação ao trabalho. Nos livros "Cidades Mortas" (1906) e "Urupês" (1914) inauguraram a crítica sobre a realidade em oposição às correntes literárias da época (romantismo), a preocupação não está relacionada a uma análise estrutural da sociedade brasileira, mas considera o caboclo como responsável pelo atraso nacional, práticas irracionais deste sujeito de "pouca instrução" o tornariam um indivíduo inútil para a nação, como aponta a autora (SILVA, 2013, p.68-69).

Dentro destas referências, retomamos a discussão sobre o termo "mamelucos" que direciona o assunto sobre a forma de pensar o homem do campo como portador de uma natureza preguiçosa e fora dos padrões civilizatórios. Segundo esta perspectiva, o encontro étnico-cultural entre europeus e índios teria resultado no surgimento dos mamelucos, união entre os colonizadores e índias, o que dava o direito do senhor europeu sobre a índia escrava. Nessa discussão introduzida por Bosi apud Enid Yatsuda aponta que:

Um dos suportes para assegurar o funcionamento do sistema colonialista, isto é, submissão do colonizado - passada a fazer do emprego da força -, é a fabricação e difusão da ideologia do colonialismo. Basicamente, o conteúdo expressa a superioridade do colonizador: é dinâmico, sensato, trabalhador, verdadeiramente cristão, participa de uma civilização superior, e seu meio de expressão, sua linguagem, é instrumento de elaboração de alta literatura. Por oposição, o colonizado é marcado negativamente, através de um mecanismo diabolicamente simples: o que é atribuído cultural, o colonizador transforma em elemento essencial. Assim o nativo torna-se, por natureza, um indivíduo preguiçoso, indolente, incapaz, idiotizado, sujo, violento, usando um falar 
rude que não pode exprimir com precisão conhecimentos mais refinados e sentimentos mais nobres. Uma linguagem inadequada à literatura (BOSI apud YATSUDA, 1992, p. 104).

Nas pesquisas científicas, Antonio Candido organiza investigações feitas a partir dos meios de vida num agrupamento de caipiras no município de Bofete (SP), nos anos de 1948 e 1954, na obra "Os Parceiros do Rio Bonito" (2001), neste mesmo estudo, o autor faz referência às descrições feitas por Cornélio Pires (1921) das variadas representações do que vem a ser o caipira ${ }^{4}$. Segundo Antonio Candido, Cornélio Pires elaborou significados e levou em conta os diversos tipos étnicos da cultura rústica paulista da época e, por isso se tornou referência no estudo da identidade caipira. Nas suas análises ele aponta que:

Para designar os aspectos culturais, usa-se aqui caipira, que tem a vantagem de não ser ambíguo (exprimindo desde sempre um modo de ser, um tipo de vida, nunca um tipo racial), e a desvantagem de restringir-se quase apenas, pelo uso inveterado, à área de influência histórica paulista. Como neste estudo não saímos dela, o inconveniente se atenua./ Cornélio Pires descreve, em um dos seus livros, o "caipira branco", o "caipira caboclo", o "caipira preto", o "caipira mulato". É a maneira justa de usar os termos, inclusive porque sugere a acentuada incorporação dos diversos tipos étnicos ao universo da cultura rústica de São Paulo - processo a que se poderia chamar acaipiramento, ou acaipiração, e que os investigou de fato num conjunto bastante homogêneo (CANDIDO, 2001, p. 27).

Dentro destas variadas representações do caipira, modos de vida e suas condições, uma das questões principais diz respeito à disponibilidade de terras. Seja em razão de situações favoráveis, nas quais o homem do campo dispõe de terras razoavelmente produtivas, ou em situações difíceis, quando mesmo possuindo um pequeno pedaço de terra, próprio ou apossado, vive para garantir a subsistência. Neste último caso, a situação da sobrevivência é complexa, pois a não legalização das terras o

\footnotetext{
${ }^{4}$ Cornélio Pires ofereceu grande importância deste tema pela obra "Conversas ao pé do Fogo" (1921) visto que já havia uma preocupação do autor sobre o que vem a ser o "caipira" enquanto identidade paulista, procurou dividir por categorias cada tipo de caipira que surgiu e que trouxe uma nova perspectiva na estrutura da vida do campo da época sem deixar de lado a identidade. Pires também inspirou-se no poema "O Poema da raça caipira" (1953) de Alberto Rovai fazendo referência a expressão da cultura caipira. Cornélio Pires também foi jornalista, músico e compositor, um dos percussores a conseguir que a indústria musical brasileira lançasse discos com músicas do gênero caipira, possível até de dizer que ele foi uns dos criadores da música sertaneja. A importância das suas obras passou a ser reconhecida quando faz citações, e é citado, nos estudos de Antonio Candido.
} 
coloca em situação de vulnerabilidade, seja em relação aos latifundiários circunvizinhos, seja em função da expansão das fronteiras agrícolas, como ocorreu em São Paulo - e ainda ocorre em diversas regiões do Brasil. Na condição de "agregado", ou posseiro, o caipira acabou "empurrado" para áreas cada vez mais despovoadas, acabando por ser representado como um sujeito às margens da história (CANDIDO, 2001, p.102). Com sua herança econômica, social e cultural, ficaram para o caipira as marcas da inadaptação para o esforço intenso e contínuo, ou para o trabalho racionalizado e voltado para o mercado, levando o mundo urbano e moderno a responsabilizá-lo por um suposto baixo nível de vida.

Nota-se que a rusticidade do viver do caipira não escapou da criação de uma representação negativa. 5 O entendimento sobre o caboclo, o homem pobre rural, esteve destinado a estereótipos pejorativos uma representação imagética do personagem Jeca Tatu, evidenciando a construção de uma figura desqualificada de uma identidade inserida no contexto econômico nacional, de uma forma caricaturada de "fungo da terra" passa de vítimas para uma raça de "depauperados e degenerados sem nome”.

\footnotetext{
Nossa montanha é vítima de um parasita, um piolho da terra, peculiar ao solo brasileiro como o "Argas" o é aos galinheiros ou o "Sarcoptes mutans" á perna das aves domesticas. Poderíamos, analogicamente, classificá-lo entre as variedades do "Porrigo decalvans" o parasita do couro cabeludo produtor da "pelada", pois que ele assiste se vai despojando a terra de sua coma vegetal até cair em morna decrepitude, nua e descalvada (LOBATO, 1978, p. 140).
}

A diferença e a identidade tendem a serem naturalizados, cristalizados ou essencializados, não obtendo eficácia se, por exemplo, a narrativa criada em torno no personagem Jeca Tatu não levasse em conta o lado sentimental e afetivo do personagem. Assim, a identidade é o ponto que define a diferença e estas duas partilham de características que resultam de atos na criação linguística que não possui valor nenhum no isolamento. A linguagem é um sistema de diferenças que se constitui no contexto de relações culturais e sociais estando sujeita a relações de poder

\footnotetext{
${ }^{5}$ Em linhas gerais, o significado geral da palavra rústico associa-se ao que é campestre, rural, ao que está relacionado ou pertence ao campo, ao ambiente rural. Rusticidade é um substantivo feminino que nomeia a qualidade daquilo que é rústico, que possui indelicadeza, grosseria, incivilidade.
} 
hierarquizadas e em constante disputa, como aponta Tomaz Tadeu da Silva (2003) O autor também aponta que a definição de identidade e diferença se tornou objeto de disputa entre grupos sociais que relativamente estão no poder. A diferenciação é o processo central para a construção da identidade e que, consequentemente, a diferença é produzida que:

\begin{abstract}
Na disputa pela identidade está envolvida uma disputa mais ampla por outros recursos simbólicos e materiais da sociedade. A afirmação da identidade e a enunciação da diferença traduzem o desejo dos diferentes grupos sociais, assimetricamente situados, de garantir o acesso privilegiado aos bens sociais. A identidade e a diferença estão, pois, em estreita conexão com relações de poder. O poder de definir a identidade e de marcar a diferença não pode ser separado das relações mais amplas de poder. A identidade e a diferença não são, nunca, inocentes (SILVA, 2003, p. 81).
\end{abstract}

Tal reflexão de Tomas Tadeu da Silva nos possibilita compreender que a identidade e a diferença se traduzem em declarações de quem pertence e quem não pertence, sendo assim, uma separação entre "nós" e “eles” e estão estreita mente ligadas às formas de classificação que a sociedade produz.

\title{
Uma modernização civilizatória para o campo.
}

O Estado de São Paulo foi palco de mudanças no período de ocupação territorial, desde a empreitada de encontrar terras produtivas para o plantio de café, com a ampliação das linhas férreas, até o avanço que culminou em apropriações e expropriações de terras. Neste último caso, a situação da sobrevivência é complexa, pois a não legalização das terras colocava o camponês em situação de vulnerabilidade, seja em relação aos latifundiários circunvizinhos, seja em função da expansão das fronteiras agrícolas, como ocorreu em São Paulo - e ainda ocorre em diversas regiões do Brasil.

Num momento em que as tradicionais lavouras nordestinas encontravam em crise, medidas políticas tomadas a partir de 1850, tais como, a "Lei Eusébio de Queiroz" criada para solucionar o problema da falta de mão-de-obra escrava e garantir o comércio interprovincial, e outra, "Lei de Terras" conhecida por reorganizar a política 
ao acesso à terra que estimulava a vinda de imigrantes europeus para trabalhar nas lavouras de café na busca por interesses lucrativos, se renovavam e ganhava um novo sentido para a posse de terras. Após a extinção do tráfico de escravos, o governo passou a estimular a vinda de imigrantes europeus para trabalhar nas plantações, ao mesmo tempo, em que reorganizou a política de acessa à terra. Aquele pedaço de terra que foi cedido para o camponês pobre agora poderia apresentar lucros para o mercado agrícola, assim o lavrador "dono", "posseiro" ou "agregado" era expulso, empurrado para outro lugar sendo submetido a reconstruir sua vida em outro lugar. Esta prática se tornou interminável nas fronteiras do estado paulista. Muitos tiveram suas terras usurpadas por grandes proprietários que chegavam com títulos nas mãos sendo forçados a vender suas terras, alguns migraram para outros lugares, outros foram absorvidos pelas fazendas como trabalhadores diretos, parceiros, sendo permitido em alguns locais ter uma "roça de comida". Neste último caso, segundo Carlos Brandão (BRANDÃO,1983, p.7-11), a situação da sobrevivência é complexa, pois a não legalização das terras colocava o camponês em situação de vulnerabilidade, seja em relação aos latifundiários circunvizinhos, seja em função da expansão das fronteiras agrícolas, como ocorreu em São Paulo — e ainda ocorre em diversas regiões do Brasil.

É a partir de 1978 que pesquisas relacionadas ao meio rural paulista tornaramse objeto de análises, questões sobre o desemprego e a segurança, tanto no meio rural quanto no urbano, a entrada da cana-de-açúcar para a produção de álcool combustível influenciou também nas políticas de acesso à terra empurrado pela crise do petróleo. No âmbito jurídico, especificamente a lei n. 8629/93, foi distribuído uma nova classificação aos imóveis rurais em pequena propriedade, média propriedade e propriedade produtiva, no entanto, a lógica de mercado para instrumentalizar a força de trabalho iguala o pequeno produtor ao assentado, que substancialmente no quesito relacionado ao latifúndio, minifúndio da empresa rural e da propriedade familiar:

Seus interesses estão, sem sombra de dúvida, muito mais próximos dos empregados rurais, do que dos grandes proprietários. Estes trabalham a terra, mas de forma indireta, determinando ordens, na condição de empregador. Os pequenos proprietários, chamados também de camponeses, usam mão-deobra paga em dinheiro, (em espécie somente em situações excepcionais, exercendo, apenas em raras ocasiões, um controle sobre o trabalho alheio) (MANIGLIA, 2002, p. 82). 
Análises como de José Graziano da Silva (1996, p.66) abordaram questões no setor econômico e populacional nas regiões brasileiras apontou que o estado de São Paulo teve o dobro do crescimento populacional no campo ( $3 \%$ a.a. contra $1,5 \%$ a.a.) no ano de 1999, e somente na região Sul do país que houve sinais de queda nas áreas rurais. Os setores que tiveram queda na produção e problemas nas receitas e despesas agrícolas, os juros e despesas bancárias que aumentaram de 5\% para 15,3\% no período de 1985-1993 devido à grande estabilidade financeira. Em outros estudos como "Velhos e novos mitos do rural brasileiro" (SILVA, 2001, p. 6) o autor aponta que o emprego de natureza agrícola vinha decaindo em todo país nos anos de 1992-1999, mas a população residente no campo voltou a crescer- ou, segundo o autor, parou de cair-, este cenário é explicado em parte pelo aumento do emprego não agrícola no campo.

As atividades não agrícolas no Estado de São Paulo que vem ganhando espaço nos bairros rurais e são conhecidos como sítios de recreio, serviços destinados ao lazer (pesque-pague, hotel fazenda, pousadas, restaurantes, spas) ou de atividades produtivas com considerável valor comercial, produção de flores, hortaliças, pomares domésticos próximo das cidades. O part-time farmer refere-se ao novo ator social consolidado no paradigma da sociedade "pós-industrial" procurando adequar atividades agrícolas e não agrícolas no campo, constitui nos agricultores em tempo parcial, além das atividades tidas como agrícolas não necessariamente somente um fazendeiro, mas, um trabalhador autônomo.

A partir da questão levantada por José Graziano da Silva (1997) outros autores como Maria Nazareth B. Wanderley (2003) apontam que tal adaptação às novas "provocações" e desafios do desenvolvimento rural numa era tecnológica. A “modernização" da organização do trabalho no campo não reproduz o modelo clássico da empresa capitalista, mesmo integrada ao mercado e respondendo as suas exigências, ela é orientada pelas novas decisões que o agricultor deve tomar nos novos contextos a que está submetido, em muitos casos permanece as estruturas da divisão do trabalho com origem na tradição camponesa não abolida. O insucesso ou minimização econômica, sem grandes investimentos e no amparo governamental, a agricultura passa a associar-se a uma "relação de negócios" que transforma as relações 
sociais no campo, supervalorizando um em detrimento do outro (WANDERLEY, 2003, p. 43-44).

O meio rural encontra-se em processo acelerado de transformações, tanto nas atividades econômicas quanto nas realidades sociais e culturais, tornou-se difícil aplicar uma definição uniforme sobre a noção de rural. Debates sobre uma possível extinção da tradição cultural fundada na prática agrícola pela lógica capitalista atual, e com ações diretas de cooperativas que oferecem amparo financeiro, mediam cada vez mais o acesso do pequeno e grande agricultor ao universo da globalização econômica, de tal modo que as reestruturações dos elementos da cultura rural veem incorporando releituras da cultura urbana. Porém, outros debates também ganham espaço como o estreitamento do vínculo com o campo, trazendo para o mundo rural possibilidades de uma qualidade de vida, de alimentação e saúde mental definida culturalmente por atores sociais que desempenham atividades que não são homogêneas e nem, necessariamente, vinculadas à produção agrícola não cabendo mais na afirmação da tendência ao seu esvaziamento social, econômico e cultural.

Análises como o de Maria José Carneiro (1997) nos alerta sobre a complexidade de analisar o processo de transformação social que acontece no campo pela visão dicotômica de campo/cidade, que acaba resultando numa visão de mundo generalizado, simplificando das relações sociais, reproduzindo a racionalidade produtiva e tecnológica dos valores urbanos. A apropriação pela cultura urbana de bens culturais e naturais do mundo rural produz uma situação que não se traduz necessariamente os valores do campo, os "neo-rurais" 6 não produzem uma ruptura com o modo de produção capitalista, mas acabam reproduzindo a ideologia burguesa, um estilo próprio de vida próximo aos padrões urbanos, contudo, em outro cenário.

\footnotetext{
${ }^{6}$ Nas análises feitas de Maria José de Carneiro (1997) o termo "neo-rurais" exemplifica os significados das práticas sociais que permeiam, tanto no campo quanto nos grandes centros urbanos, movimentos de pluriatividade e a cultura country. No processo de pluriatividade, a integração da aldeia à economia e à sociedade global, realizando inovações agrárias, turísticas e culturais permitindo adaptarem-se as necessidades econômicas e técnicas a favor da sua existência e o sistema de valores. A cultura country, no âmbito da feira agropecuária a cidade se ruraliza, promovendo uma inserção singular do rural no mundo geral, desvencilhando da noção que o associava ao tradicional, sendo uma afirmadora do mundo rural com o mundo urbano, expressão de modernização do rural (CARNEIRO, 1997, p. 59-60).
} 
O desaparecimento da fronteira entre rural e urbano, a expansão de novas reflexões sobre os instrumentos analíticos elaborados para compreender o universo rural, continuam qualificando espaços e universos sociais nas sociedades contemporâneas sustentados na dualidade das categorias genéricas. Entre esses instrumentos, segundo Maria José Carneiro, em dados colhidos e analisados da Pesquisa Nacional por Amostra de Domicílios (PNAD) realizada pelo IBGE no ano de 2000 que demonstra que:

No Brasil, ainda que mais de dois terços da população estejam contabilizados como "urbana" (IBGE, 200o), a maioria dos habitantes dos pequenos municípios está nas áreas rurais. Segundo os dados da PNAD, a população rural brasileira vem aumentando a partir da segunda metade da década de 90, recuperando uma taxa de crescimento anual ( $1,1 \%$ ao ano) muito próxima do crescimento da população total no mesmo período ( $1,3 \%$ ao ano), apesar das diferenças entre regiões do país. Em São Paulo observa-se uma maior revitalização do mundo rural, ao passo que a região Sul o movimento de esvaziamento do campo ainda é predominante. Mas o interessante é que esse movimento de retração do êxodo rural é acompanhado pelo declínio expressivo das ocupações não agrícolas, que, segundo os dados da PNAD, passam a crescer a uma taxa anual de 6,1\% no período 1996-1999 (CARNEIRO, 2008, p. 17).

Assim, o tema lida também com a ambiguidade que de dois elementos para reflexão, uma seria a permanência da dicotomia entre rural e urbano, e a outra, das pequenas cidades formalmente definidas como urbanas entre pequenos municípios que estariam na mediação de dois códigos de relações sociais, a integração do mundo rural com o sistema mais geral de cidades e a vinculação com a natureza (CARNEIRO, 2008, p.20). E podendo até incluir uma terceira reflexão que estaria no debate já proposto por Serge Gruzinski (2001) dentro da problemática sobre o contato entre europeus e ameríndios e seus resultados refletidos na complexidade do jogo do neoliberalismo, da modernidade e da globalização econômica, sendo estas que proliferam fenômenos que embaralham nossas referências habituais: misturas das culturas do mundo, multiculturalismo e recuos identitários sob formas que vão desde a defesa das tradições até as expressões de xenofobia e purificação étnica (GRUZINSKI, 2001, p.16). 


\section{As cooperativas, modernização e globalização econômica}

Há pesquisas de campo que abordam sobre o esvaziamento das áreas rurais devido ações diretas das cooperativas. Um dos trabalhos que podemos citar é a dissertação de Mestrado - "Permanências em movimento- resistência familiar no bairro rural Taquaruçuzinho em Frutal do Campo (SP)” (2019) - em que é levantada a questão sobre o impacto das ações das cooperativas aos pequenos agricultores da área rural do município de Cândido Mota (SP) sobre o endividamento e a compra/venda das propriedades de pequenos agricultores que possuíam propriedades na região, que na qual, observa-se a presença, cada vez mais intensa, do agronegócio com demanda para atender usinas de açúcar e álcool.

O cooperativismo tem por princípio a facilidade de inserção e participação mais ativa na economia, com auxílio e o fortalecimento das atividades produtivas bem como o acesso a novas ferramentas, maquinários, tecnologias, crédito, oportunidade de ingresso em mercados mais competitivos, vantagens fiscais que possibilita para o pequeno agricultor a oportunidade de fortalecer sua atividade produtiva, através do ingresso em associações e cooperativas. Porém, não é possível compreender as modificações sem integrá-las aos movimentos políticos, econômicos, culturais e simbólicos, marcados pelas revoluções modernas como a Revolução técnico-cientifica, entre as concepções da relação entre o meio urbano e rural7. As representações dominantes de uma sociedade estão relacionadas ao exercício do poder, domínio do Estado e do poder hegemônico que produzem representações do espaço e influenciam na produção de símbolos, códigos, e sistemas de signos dominantes de uma sociedade. Tal poder, centrado na cidade moderna capitalista, produz signos de territorialidades, tanto do rural quanto do urbano, redefinindo seus papeis e identidades que são alterados por atores que detém deste poder. Ao se referir ao espaço socialmente

\footnotetext{
7 Podemos citar aqui também um movimento que ficou conhecido como "Revolução Verde", processo de intensa modernização da agricultura vivida na segunda metade do século XX, nos Estados Unidos e na Europa, que impactou drasticamente a produtividade na agricultura, elevando os níveis de produção e implicando um uso intensivo de produtos industriais no campo.
} 
construído, territorializado, que expressa um lugar de relações, apropriações e dominações podemos refletir que

Este tipo de representação tem a capacidade de dar conta da dinâmica das ações apreendidas no espaço e isso é importante, porque ela está em constante transformação ao longo da história (bem como as relações de poder), influenciando a permanente redefinição desse espaço e, consequentemente, do território. É a essa concepção de espaço, feito território, que nos referimos daqui à adiante (RUA, 2005, p. 46).

O entendimento sobre as desigualdades em espaços periférico-rurais dominados pelos centros urbanizados reproduz a dicotomia atrasado/avançado. O espaço rural e o espaço urbano, campo e cidade, integram a mesma racionalidade espacial marcada pela organização a partir da cidade, da indústria, da terceirização na sociedade contemporânea, bases reprodutivas do capitalismo e a polarização construída entre estes é exercida pela lógica das relações agrícolas, não levando em conta as interações sociais presentes no espaço como um ambiente de produção fabril onde a terra somente produz algo, sendo vazio de relações sociais.

\footnotetext{
O próprio termo cidade (em suas múltiplas origens) é apropriado para criar a representação social do "burguês polido, político, educado, cidadão". O rural rus, ruris, em latim, que derivou em rude- passa a ser visto como o "outro, nessas representações". Com os estudos a respeito do desenvolvimento, posteriores à Segunda Guerra Mundial, em que enfatizou o tecnológico em detrimento do social e das comunidades (visão predominante até hoje), o rural foi sendo construído como sinônimo de agrícola, o que acelerou, mais ainda, as dicotomias existentes. Também na política oficial o rural tem sido percebido como agrícola (ligado apenas à produção); a agricultura de exportação, tecnicamente avançada, tem sido privilegiada, enquanto a agricultura de mercado interno foi chamado de "agricultura de subsistência" e considerado os pequenos agricultores (proprietários ou não) como incapazes de acompanhar o progresso técnico, econômico e social (RUA, 2005, p. 48).
}

A preocupação em modernizar o campo nos anos finais do século XX estava em responder às exigências do mundo globalizado, acompanhar a demanda de "racionalidade" a ser empregada no plantio, nos cuidados, na colheita, na armazenagem, estocagem, empacotamento, transporte e comercialização justificando assim o surgimento de instituições de ensino e de pesquisa aplicada na área da agricultura. O movimento modernizador, a partir de 1970, acelerou as grandes produções no campo que modificaram também as formas de emprego rural e as 
relações de trabalho no setor, auxílio ao crédito foi um dos investimentos do estado de São Paulo. Segundo Carla Julião da Silva (2019) só o estado de São Paulo recebeu 33\% do montante total disponível e tais estímulos, gerados pelo crédito, a monocultura volta a ser privilegiada e o interior rural paulista, especificamente a região do município de Cândido Mota, passa a ter um novo cenário.

Após a geada da década de 1970 e a desativação das estradas de ferro locais,
inicia-se na região centro oeste paulista um forte êxodo rural e,
consequentemente, um aquecimento do terceiro setor e o crescimento das
áreas urbanas locais. Com a elevada taxa de urbanização das principais
cidades da região, o crescimento dos latifúndios tornaria inevitável, fazendo
que os grandes proprietários de terra incorporassem as pequenas
propriedades que pertenciam aqueles que deixavam a vida no campo para
tentar algo novo nas cidades. Os incentivos governamentais no começo da
década de 2000 estimularam a produção de álcool e a expansão da produção
de cana de açúcar. A instalação de usinas e empresas do ramo trouxeram para
a região vagas de emprego para pessoas que quisessem atuar como cortadores
de cana. Os interessados vindos de outras cidades paulistas e até de outros
estados fixaram-se na região em busca de oportunidades (SILVA, 2019, p.33-
34).

A agricultura familiar tem sobrevivido em meio à competição de condições e recursos orientados para favorecer a monocultura e as grandes propriedades. Nesse sentido, as cooperativas são concebidas pela sua capacidade de organizar o espaço e a produção rural e se identificam como uma alternativa capaz de organizar a atividade produtiva, potencializando as vantagens da agricultura familiar e revitalizando os territórios. Porém, os pequenos agricultores precisam constantemente lidar com a presença, ou "ajuda”, das cooperativas que fazem a mediação do agricultor com setores financeiros e os meios de produção (insumo, tratores, colhedeiras, plantadeiras, sementes, silos de armazenagem de grãos, entre outros.) ditando regras de plantio que acabam subordinando o pequeno agricultor a seguir tais regras para conseguir manter as estruturas de uma produção agrícola.

Os territórios rurais refletem os modos de produção capitalistas, dinâmicas acumulativas, aparato técnico e tecnológico produzido pelas grandes corporações multinacionais, a competitividade da produção no mercado e a corrida para manter um alto nível da escala de produção. Nesta perspectiva, a terra ao se tornar mercadoria passa consequentemente a ter valor de uso e de troca, sendo uma de suas 
consequências, a relação de dependência da agricultura (e do agricultor) com acesso a créditos financeiros para se manter ativos no mercado, numa concorrência desleal entre os pequenos e os grandes agricultores.

\section{Considerações finais}

Ainda não há um esgotamento do assunto relacionado ao rural brasileiro tão pouco colocar a terra somente como um objeto de trabalho como expressão de um fator produtivo sem considerar os valores sociais nela contida. O intenso campo de reflexão, que embora ultrapasse os limites de uma estrutura acadêmica, o valor conceitual sobre a categoria agricultura familiar sofre dificuldades do ponto de vista teórico. Para uns, o conceito agricultura familiar se confunde com a definição operacional adotada pelo Programa Nacional de Fortalecimento da Agricultura (Pronaf), para outros, corresponde a uma determinada camada de agricultores, capazes de se adaptar às modernas exigências do mercado em oposição aos demais "pequenos agricultores", os chamados agricultores "consolidados”, ou que tem condições em curto prazo de se consolidar, assim, outras configurações de produção e forma social oferece elementos analíticos e ocupam um lugar importante no cenário atual da economia e sociedade brasileira (WANDERLEY, 2003, p. 43-44).

É possível encontrar referências literárias sobre a territorialização do agronegócio no campo brasileiro, cooperativas, inclusive no interior do Estado de São Paulo, questões sobre a trajetória histórica e de tradição religiosa nos bairros rurais, ${ }^{8}$ porém, desdobramentos no trabalho empírico ainda são mínimos, tanto sobre as cooperativas ativas em pequenas regiões do estado de São Paulo. 9

A estrutura social, político-econômica nacional se mantém largamente amparada nas atividades agropecuárias, sendo este, um tema de relevância para as

\footnotetext{
8 Sobre este assunto podemos citar: José Eli Veiga. A Dimensão rural do Brasil. Estudos Sociedade e Agricultura (2004); Élen Angela Silva. A festa do encontro, festa dadivosa: a trezena franciscana na região rural de Tabocas em Abaté/ MG. Dissertação (2014); Luciana de Oliveira Chianca. "Quando o campo está na cidade: migração, identidade e festa" (2007).

9 Sobre estes temas podemos citar os trabalhos de: Bernardo Mançano Fernandes (1999); Rogério Haesbaert (2004); Marcos Aurélio Saquet (2007); Bernadete Maria Coelho Freitas (2012); Geraldo Delgado (2013) entre outros.
} 
ciências sociais brasileiras contemporâneas. A ruralidade permanece como uma das principais bases de sociabilidade no Brasil, transformando-se ao longo do tempo e contribuindo, assim, para a composição da modernidade brasileira. Porém, abordagens destes temas que contemplam somente a ótica da relação econômica do rural versus urbano pautado somente numa posição de atraso versus avançado põe em relevo uma característica importante dessa dinâmica que é a dificuldades de compreender o componente racial associado a construções de diferenças entre o que é do universo rural e urbano. Estudos sobre miscigenação e racialidade nos auxiliam para compreender como são construídos alguns traços determinantes de características relacionadas ao fenótipo, à inferioridade ou a incivilidade, arquitetando características para uma representação identitária genérica e pejorativa, de inferioridade física, moral e intelectual, que serviu de base para representação imagética do caipira paulista.

\section{Referências}

ADUB, Katia Maria. A ideia de São Paulo como formador do Brasil. In: FERREIRA, A. C. (org.). Encontros de História. São Paulo: EDUNESP/FAPESP/ANPUH, 1999.

ANDRADE, Thiago Oliveira; GANIMI, Rosângela Nasser. Revolução Verde e apropriação capitalista. CES Revista, v. 21, p. 43-56. Juiz de Fora, 2007. Disponível em: $<$ https://bit.ly/2RWQduL>. Acesso em: o6 de julho de 2021.

ANDREWS. G. R. Negros e brancos em São Paulo (1888-1988). Bauru/SP. TraduçãoEdusc, 1998.

BRANDÃO, Carlos Rodrigues. Os caipiras de São Paulo. São Paulo: Brasiliense, 1983.

CANDIDO, Antonio. Os Parceiros do Rio Bonito: estudo do caipira paulista e a transformação dos seus meios de vida. Rio de Ja neiro. Ed. Ouro sobre Azul, 2001.

CARNEIRO, Maria José. Ruralidade: novas identidades em construção. Texto publicado nos Anais do XXXV Congresso da Sociedade Brasileira de Sociologia e Economia Rural. Natal, agosto, 1997.

. "Rural” como categoria de pensamento. Ruris. Volume 2-nº 1. Páginas 10-38. Março de 2008.

FERNANDES, Florestan. O negro no mundo dos brancos. São Paulo. Editora Global, 2007. 
FREYRE, Gilberto. Casa Grande \& Senzala: formação da família brasileira sob o regime da economia patriarcal. São Paulo: Editora Global, 2006.

GRUZINSKI. O pensamento mestiço. Companhia das Letras: São Paulo, 2001.

KERN, Gustavo da Silva. Gilberto Freyre e Florestan Fernandes: O debate em torno da democracia racial no Brasil. Revista Historiador Número o6. Ano o6. Janeiro de 2014. Disponível em: <http://www.historialivre.com/>. Acessado em 03/07/2021.

LOBATO, Monteiro. Urupês. São Paulo. Editora brasiliense. 23 $3^{\underline{a}}$ edição, 1978.

MARTINS, José de Souza. A Modernização e problema agrário no Estado de São Paulo. São Paulo Revista do Instituto de Estudos Brasileiros, no 6. Universidade de São Paulo. 1969.

A luta pela terra. São Paulo. Ed. Paulus. 1997.

MENDRAS, Henri. Sociologia Rural. Rio de Janeiro. Zahar Editores, 1969.

MONTEIRO, J. M. Negros da terra: índios e bandeirantes nas origens de São Paulo. São Paulo: Companhia das Letras, 1994.

PARRILLA, Aline Franciele. Chico Bento, um caipira do campo ou da cidade?: a representação do espaço rural e urbano e de seus habitantes na revista em quadrinhos do Chico Bento (1982-200o). Dissertação (Mestrado em História e Sociedade) Faculdade de Ciências e Letras - UNESP, Assis, mímeo, São Paulo, 2006.

PIRES, M. L. L. S. O Cooperativismo Agrícola como uma forma de neutralizar as desvantagens competitivas da agricultura familiar. Em análise a Coopercaju. In: XXXIII Congresso Brasileiro de Ciências da Comunicação, Caxias do Sul, RS, Brasil, 2010.

POLLAK. Michael. Memória e identidade social. Estudos Históricos. Rio de Janeiro. Vol.5, n.10, p.200- 212, 1992.

QUEIROZ, Maria Isaura Pereira. O Campesinato Brasileiro. Ensaios sobre a civilização e grupos rústicos no Brasil. Petrópolis. 2a edição. Vozes, 1976.

Bairros Rurais Paulistas. Dinâmica das relações bairro rural-cidade. São Paulo: Livraria Duas Cidades, 1973.

REIS, Jussara Christina dos. "A gente é nascido e criado aqui". Memória e territorialidade no bairro Boa Vista, Bragança Paulista- SP. Dissertação de Mestrado. Programa de Pós-graduação em Ciências Sociais- UNESP - campus de Marília. Mímeo. Marília/SP, 2012. 
RIBEIRO, Darcy. O povo brasileiro: a formação e o sentido do Brasil. São Paulo: Companhia das Letras, 2006.

STEPAN, Nancy Leys. A hora da eugenia: raça, gênero e nação na América Latina. Rio de Janeiro: Fiocruz, 2005.

SEYFERTH, Giralda. A invenção da raça e o poder discricionário dos estereótipos. Rio de Janeiro. Tempo Brasileiro. Anuário Antropológico/93, p. 175-203, 1995.

SILVA, Luciana Meire. O Brasil rural nas obras de Monteiro Lobato nas décadas de 1910 e 1930. Tese de Doutorado em Ciências Sociais pela Faculdade de Filosofia e Ciências, UNESP campus Marília, mímeo, 2013.

SILVA, Sergio. A expansão cafeeira e origens da Indústria no Brasil. São Paulo: Editora Alfa Omega, 1976.

SILVA, Tomaz Tadeu da. Identidade e Diferença. A perspectiva dos Estudos Culturais. Petrópolis/RJ: Editora Vozes, 2003.

YATSUDA, Enid. O Caipira e os outros. In: BOSI, Alfredo. Cultura Brasileira: temas e situações. São Paulo. Editora Ática, 1987.

WANDERLEY, Maria Nazareth Baudel. Agricultura familiar e campesinato: rupturas e continuidade. Estudos Sociedade e Agricultura, Rio de Janeiro, p. 42-61, 2003. 